\title{
PROGRESSO E MIMESIS: IDEIAS POLÍTICAS, IMITAÇÃO E DESENVOLVIMENTO
}

Robert Chisholm*

As recentes dificuldades de constituir governos estáveis e efetivos no Afeganistão e no Iraque após o inquestionável triunfo dos Estados Unidos no campo de batalha têm realçado uma importante lição de política: o maior problema no estabelecimento de um regime político é garantir a base de autoridade. A experiência de descolonização do segundo pós-guerra, as transições do autoritarismo dos anos 1970 e 1980, e o colapso da experiência soviética nos 1990 revelaram, ou deveriam ter revelado que, para Estados em processo de transição estrutural de um regime para outro, o problema da autoridade é agravado em razão de que instituições devem ser criadas, e a legitimidade deve ser criada ou resgatada. A ciência política comparada vinha ignorando o papel central que ideias e modelos políticos têm na criação e no desenvolvimento de instituições. Durante os períodos de domínio do behaviorismo e do estruturalismo na ciência política, as ideias não foram aceitas como

\footnotetext{
* Artigo originalmente publicado na New England Journal of Political Science, vol. 2, n ${ }^{\circ}$ 1 (Spring 2005). Disponível em: http://nepsagas.ehost.com/nejps/vln2/. Tradução de Carolina Coelho Brandão.
} 
variáveis explicativas, mas com o colapso do bloco soviético e a efervescência intelectual que acompanhou este evento, criouse uma fresta pela qual os efeitos de ideias no desenvolvimento político poderia tornar-se central na política comparada.

Uma forma de abordar este problema é examinar como ideias são adotadas, adaptadas e assimiladas pelos atores políticos, especialmente aqueles que também articulam ideias dentro de uma elite política para argumentar a favor ou contra determinados modelos políticos. Na medida em que as ideias articuladas por pensadores políticos guiam ações, refletem entendimentos dominantes entre as elites sobre a realidade ou fornecem uma base para a crítica desses entendimentos, o estudo de tais ideias irá revelar um pouco do esforço de constituir um regime, pelo menos quanto à forma pela qual os atores entendem o que estavam fazendo. Isso é verdade especialmente ao vermos como o aparente triunfo do modelo de Estado e sociedade no norte do Atlân106 tico gerou um renovado (e revisado) interesse na forma pela qual o desenvolvimento de democracias industriais avançadas pode ser reproduzido nos países em desenvolvimento, ao mesmo tempo que esse modelo também tem provocado uma reação forte e hostil contra seus próprios princípios.

Como no século XIX, os regimes liberais e constitucionais do norte do Atlântico são os modelos predominantes de desenvolvimento para aquelas áreas do mundo que buscam se desenvolver, mas também são alvo de uma crítica vigorosa e uma escancarada hostilidade que está enraizada em ideias tradicionais, elas mesmas, muitas vezes, adaptações modernas das tradições que pretendem representar. As instituições na comunidade do norte do Atlântico estão sendo copiadas, suas práticas imitadas, seus valores adotados tanto no antigo Terceiro Mundo quanto nas economias em transição do ex-Bloco Soviético. A aceitação dos Estados do norte do Atlântico como modelos de desenvolvimento terá grande significado para os Estados que buscam emulá-los, além de 
ser importante a forma pela qual as ideias que sustentam e legitimam esses modelos são entendidas, adaptadas e transformadas em ações, assim como seu fracasso irá indubitavelmente engendrar reações contra esses modelos. De qualquer maneira, a imitação de um modelo não é garantia de que seu produto será reconhecido como o original. Há um processo de adaptação e de assimilação que acompanha a imitação, e este pode transformar as ideias. O resultado pode se diferenciar enormemente do original, criando a necessidade de entender o processo de imitação, adaptação e assimilação de ideias e modelos recebidos do Atlântico norte como um padrão de desenvolvimento político de longa data.

\section{Desenvolvimento político sem ideias}

Apesar de a afirmação de que as ideias importam na política parecer quase banal de tão óbvia, vale a pena notar que, em termos gerais, desde a revolução behaviorista, a ciência política tem relegado às ideias um papel no máximo secundário no estudo de política comparada. Enquanto cientistas políticos do pós-guerra investigaram extensamente as precondições necessárias para o desenvolvimento político (entendido basicamente como a criação de um sistema político que implicava o regime liberal e democrático), muito desse trabalho funcionava dentro da noção de que seu objeto de pesquisa era essencialmente o comportamento (behavior). Em outras palavras, estavam preocupados com uma realidade social objetiva da qual identificariam padrões repetitivos de ações que poderiam estar correlacionados com determinadas crenças ou valores. As crenças e valores identificados pelos investigadores foram caracterizados pelo grau em que serviam como base para o modelo político desejado e eram eles mesmos um produto de condições sociais objetivas. Esse enfoque excluía sistematicamente as ideias do estudo político, ao relegá-las à esfera de crenças subjetivas, suscetíveis a mudanças e a manipulações, tendo papel secundário quando comparadas a condições 
objetivas (Taylor, 1979; Wolin, 1973). Da mesma forma, instituições e arranjos institucionais eram tratados sem referência às ideias políticas que encarnavam ou representavam; eram simplesmente arranjos funcionais para articulação, agregação e adjudicação de interesses (Almond e Verba, 1963). Independente do valor da revolução behaviorista na ciência política, tal perspectiva e sua manifestação particular como teoria modernizadora apequenaram tanto as ideias como a história na tentativa de criar um enfoque científico para o desenvolvimento político (Tholfsen, 1984, esp. Cap. 6).

A reação ao behaviorismo, que surgiu na década de 1960 e encontrou espaço nos estudos políticos de perspectiva estruturalista, principalmente no Terceiro Mundo, também negou o papel modelador das ideias na política. Teorias de dependência, subdesenvolvimento e autoritarismo burocrático ignoraram as ideias, salvo quando disfarçadas como ideologia, tomando-as como um epifenômeno da base 108 econômica da sociedade. De forma similar, teorias sobre a autonomia do Estado baseadas nas características estruturais da sociedade, da economia ou das necessidades do capital também relegaram à irrelevância o papel das ideias, já que nessas teorias o pensamento das pessoas tinha menos importância do que suas relações como portadores de necessidades e possibilidades. Importantes trabalhos dessa tradição não têm índices de registros (index entries) de ideias e muito menos uma discussão séria das ideias como construtoras de instituições, estruturas ou atividades políticas (Frank, 1967, 1969; Cardoso e Faletto, 1979). Até Guillermo O’Donnell, que reconhece a formação norte-americana de muitos latino-americanos que desempenharam papel importante no desenvolvimento do autoritarismo burocrático, enfatiza a necessidade estrutural de uma resposta tecnocrática à crise de acumulação (O’Donnell, 1979, pp. 76-85 e 53-67).

Curiosamente, no entanto, a falta de preocupação com as ideias também aparece em uma abordagem que, aparen- 
temente, necessitaria delas: a cultura política. Uma versão popular e poderosa de teoria da cultura política, frequentemente aplicada à América Latina, procura explicar a região em termos de traços culturais profundos que modelaram instituições e valores durante a longue durée. Essa análise da cultura latino-americana frequentemente trata o papel das ideias meramente de passagem, mas normalmente de forma mais substancial, mirando a influência formativa das ideias e instituições que derivam da Ibéria medieval. Howard J. Wiarda, por exemplo, que há muito vem defendendo o entendimento da América Latina em termos de seu desenvolvimento particular e não dentro de modelos norte-americanos, enfatiza a importância da herança cultural da Ibéria na América Latina e insiste em que valores hierárquicos e autoritários formaram profundamente a política latino-americana. Contudo, discute ideias principalmente em termos da grande influência da escolástica ibérica e do neotomismo ou da democracia orgânica e corporativa de Rousseau, em contraste ao lockeanismo da América anglicana, em vez de examinar o pensamento político de teóricos que deram forma às instituições da América Latina (Wiarda, 1973, 1979, 1992). Até mesmo o último trabalho de Wiarda, em que trata as ideias de pensadores políticos latino-americanos bem mais explícita e extensamente do que no passado, com seus capítulos sobre o liberalismo, positivismo, nacionalismo, marxismo e corporativismo, assim como suas referências extensas a vários autores europeus e latino-americanos, é influenciado pela noção dominante de valores, não realizando um estudo detalhado das ideias debatidas por latino-americanos e articuladas nas instituições constitucionais (Wiarda, 2002). Da mesma forma, Richard Morse tem argumentado que a América Latina tem de ser entendida em termos das forças endógenas que a formaram, mas ele também tende a tratar ideias políticas como um aspecto ou um reflexo da cultura, como valores, e não como algo formulado e manipulado 
por indivíduos em determinadas épocas e lugares com consequências específicas. Curiosamente, enquanto o tratamento de Morse a diversos pensadores individuais é frequentemente bem sensível e cheio de nuances, o uso consciente das ideias, seu papel na formação de instituições que foram deliberadamente planejadas e, principalmente, o explícito tomar emprestado de ideias, de exemplos e fontes estrangeiras é tratado mais como uma excentricidade do que como um fator formador importante da política contemporânea latino-americana (Morse, 1964, 1989, 1992, 1996).

Outra versão da perspectiva da cultura política atualiza elementos da teoria da modernização, novamente interpretando a política meramente como um reflexo de atributos culturais profundos ou de atitudes subconscientes, como era o caso dos behavioristas. Nessa leitura da cultura política, certas atitudes ou valores retardam o desenvolvimento que pode ser determinado pela mistura correta de imigrantes ou 110 reformas educacionais que nutririam novos valores sociais (Harrison, 1985; Harrison e Huntington, 2001). O desenvolvimento pode, portanto, ser tratado como um produto "carregado de memes ${ }^{1}$ ", para usar o novo jargão, ao invés de um produto da intencionalidade humana (Dennett, 1995). Uma variação disso, que trata as ideias mais seriamente, enfatiza a importância de experiências de aprendizagem e o papel das elites intelectuais em receber e difundir ideias e valores. Assim, David Landes menospreza a influência maligna da dependência ideológica adotada pelos intelectuais latino-americanos, "ruim para os esforços e a moral", "nutrindo uma propensão mórbida para encontrar defeitos em todos menos em si mesmo" e, finalmente, como sendo responsável por "promover impotência econômica" (Landes, 1999, p. 328). Apesar de ter a virtude de considerar seriamente o papel das ideias, isso não ajuda em nada o nosso

\footnotetext{
${ }^{1}$ N.T.: Refere-se à unidade mínima da memória, termo usado por Richard Dawkins.
} 
entendimento da forma pela qual as ideias se encaixam em circunstâncias sociais, afetando-as ou mudando-as.

Mais recentemente, entretanto, a "Terceira Onda de Democratização", que já dura um quarto de século e presenciou o colapso de governos autoritários e totalitários ao redor do mundo - totalmente imprevisível tanto para a ciência social behaviorista quanto para a estruturalista -, parece ter levado a ciência política à apreciação da importância das ideias e da intencionalidade na formação de instituições e ações políticas. Esse retorno pode ser encontrado implicitamente no ressurgimento do interesse no design institucional e no entusiasmo geral pela "sociedade civil" como apoio para a democracia. Em ambos os casos, o papel de ideias sustentadas conscientemente em debates sobre o que precisa ser feito, em vez de "valores" não refletidos e associados a determinados comportamentos ou à mistificação ideológica simples, tem reingressado no campo de visão da ciência política. Não é raro encontrar livros e artigos que examinem a performance de instituições liberais democráticas específicas, de práticas e arranjos constitucionais (ou o impacto de sua ausência) nos países em desenvolvimento ou em "transição", algo que era praticamente inimaginável nos dias de domínio behaviorista e estruturalista que precederam a última parte da década de 1980 (ver Baaklini, Denoeux e Springborg, 1999; Lijphart, 1992; Valenzuela, 1994; Baaklini e Defosses, 1997; e Weimer, 1997). O significado disso está na importância dada à intenção e à conceitualização da criação e do funcionamento de tais instituições, que é reconhecido por autores que discutem a necessidade de um planejamento cuidadoso. É impossível saber se isso resultará em um progresso significativo no estudo de política comparada, mas sua mera ocorrência indica uma mudança importante da mistura de ideias, normas e valores, e no tratamento deles todos simplesmente como um resultado impensado da socialização ou de algum outro processo social "objetivo" que tenha prioridade explicativa. 
Uma outra perspectiva olha para as decisões dos atores políticos, fazendo da escolha estratégica o objeto de estudo. Esse enfoque, cujos defensores argumentam que o desenvolvimento político é o resultado eventual da competição de interesses variados, tem o mérito de levar a sério as ações dos atores políticos, considerando-os racionais em seus cálculos e tratando posições políticas como articulações conscientes de interesse e desejo, em vez de meras atitudes (Ames, 1987; Geddes, 1994; Schneider, 1991). Autores que trabalham a partir desse enfoque específico buscam entender como os atores têm procurado conscientemente o desenvolvimento de políticas e, muitas vezes, também de instituições que aparecem como resposta a determinadas situações. Entretanto, o efeito que as ideias políticas têm na criação das regras do jogo ou das estruturas nas quais os atores têm de se movimentar é frequentemente ignorado ou tratado como algo inerente, em vez de ser transformado em objeto de estudo, como é o 112 caso do trabalho de Schneider, em que ele nota que:
"os trilhos da estratégia de desenvolvimento do Brasil foram estabelecidos muito antes da década de 1970; e a tentativa de definição do modo pelo qual mover-se por esses caminhos causou então choques entre interesses e preferências" (1991, pp. 200-202).

Ele não se preocupa, todavia, com quem construiu os "caminhos" ou como e por que eles foram feitos, apesar de reconhecer que "preferências ideológicas" possam ajudar a explicar as diferenças entre o Brasil e outros países industrializados tardiamente (Schneider, 1991, pp. 200-202). Novamente, o relegar das ideias a expressões de interesse ou ideologia é algo que arrisca menosprezar o impacto do pensamento na vida.

Finalmente, existe o que pode ser chamado de estudo de política "de baixo". Ele carrega uma semelhança com o enfoque que olha a história buscando afastá-la do estudo 
sobre assuntos de elite, procurando "a história do passado das pessoas comuns... escrita do ponto de vista das pessoas comuns"(Burke, 1996, p. 368). Na ciência política, esse desdobramento se expressa num enfoque que procura explicar o desenvolvimento político como o resultado de "resultados imprevisíveis de lutas de atores sociais e estatais" (Addis, 1997, p. 135). Enquanto muito trabalho bom foi feito sobre a mobilização de grupos antes marginalizados e sua entrada na arena política, transformando-os de objetos em sujeitos da história, a maioria não chega a investigar o papel histórico das ideias na construção de instituições políticas (Seidman, 1994; Wolfe, 1993; Alvarez, 1990). Esse é o caso da literatura mais antiga sobre os chamados "novos movimentos sociais" e a "sociedade civil", que observam as ideias como inspiração ou alegam que a luta trouxe uma mudança na consciência, mas encaixam ideias de forma não problemática numa narrativa de democratização e progresso sem se preocupar com a forma pela qual essas ideias são entendidas ou manipuladas pelos próprios atores. Aqueles que escreveram sobre isso, especialmente sobre a sociedade civil, frequentemente parecem ter projetado suas próprias ideias nos movimentos de massa que eles viram se desenvolver no Terceiro Mundo, vendo-os como mais puros do que os partidos políticos e os grupos de interesse (Cohen e Arato, 1992; Keane, 1987 e 1988), sem examinar como esses grupos entendiam as ideias que eles, supostamente, encarnavam desinteressadamente (muitas vezes usando, de forma autoconsciente, a retórica dos "idealistas" do Primeiro Mundo para avançar uma agenda de grupos de interesses relativamente comum) ou o próprio papel de tais grupos como atores políticos bastante convencionais ${ }^{2}$.

\footnotetext{
${ }^{2}$ A tendência a tratar como fetiche a natureza supostamente apolítica e desinteressada da sociedade civil e os "novos movimentos sociais" associados a ela é criticada por Kumar (1993) e Seligman (1992).
} 
Nenhuma das diversas perspectivas da literatura contemporânea sobre desenvolvimento político nas chamadas "transições" se concentra no papel histórico das ideias na formação de instituições ou nas ações políticas. Ao invés disso, a história das ideias políticas limita-se apenas a um compartimento fechado próprio, isolado das discussões sobre como as instituições políticas se desenvolvem ou por que as pessoas agem politicamente. Exceção são os raros casos em que ela é tratada como uma categoria residual que serve para cobrir o que não pode ser encaixado facilmente nas perspectivas dominantes. Então, as reflexões dos participantes sobre experiências reais são negligenciadas, enquanto os teorizadores do desenvolvimento formulam novas teorias com pouca consciência da possibilidade de aprendizagem a partir de ideias históricas produzidas em períodos análogos. A bizarrice de tal perspectiva é evidenciada quando contrastada com escritores de países que escaparam do autorita114 rismo ou do totalitarismo soviético nos anos 1980, para os quais o poder das ideias é tema central. Um exemplo particularmente notável do tratamento das ideias e o seu apelo às classes intelectuais e políticas é A suburb of Europe: nineteenthcentury Polish approaches to Western civilization (1999), de Jerzy Jedlicki. Originalmente escrito no fim dos anos 1970, este estudo sobre as tentativas dos intelectuais poloneses de importar ideias ocidentais para desenvolver sua sociedade e para preservar sua identidade em oposição ao domínio russo foi censurado até 1988 pelo regime polonês ligado aos soviéticos, por razões óbvias. O trabalho ressalta o esforço de se apropriar de ideias ocidentais e reconciliá-las à situação particular do Reino Polonês na Rússia posterior às divisões do fim do século XVIII. É um esforço que coloca "progresso", por meio da imitação de exemplos estrangeiros, contra "tradição”, em um padrão de reiteradas oposições. Este embate entre progresso e tradição na elite polonesa e o choque das ideias de progresso com a realidade da condição polonesa 
levou à adaptação e à reformulação de ideias em ambos os lados, o que influenciou ações futuras. A possibilidade de ação era limitada pela ocupação da Polônia e pela dominação do Império Russo. Portanto, a riqueza potencial da perspectiva polonesa sobre a civilização ocidental foi restringida pela falta de poder político para implementar programas de imitação, o que limita o caso polonês. De qualquer forma, o problema do "progresso", o embate entre "progresso" e "tradição" ou entre "cosmopolitismo" e "cultura nacional", e o choque de ideias e modelos com realidades sociais e econômicas são experiências comuns, e todas elas são encontradas na experiência brasileira dos séculos XIX e XX.

O Brasil é um produto do colonialismo europeu, localizado na periferia da cultura e da consciência europeia. Seu desenvolvimento durante o século e meio entre a Revolução Francesa e o começo da Guerra Fria serve de exemplo de como a imitação de modelos políticos liberais dos Estados industrializados do norte do Atlântico afetou e foi afetada pelo contexto de um país menos desenvolvido. As várias tentativas de modernizar o Brasil por meio da imitação das instituições políticas e econômicas do norte do Atlântico ou da adaptação seletiva de alguns dos aspectos desses modelos envolveram um processo intelectual que foi expresso muitas vezes de forma consciente em trabalhos de teoria política. Assim, muito pode ser aprendido com a maneira como certas ideias da Europa e dos Estados Unidos foram selecionadas, alteradas e, depois, usadas por pensadores e atores políticos brasileiros.

Tal perspectiva faz parte da tradição da cultura política, uma vez que existe a preocupação com crenças, valores e ideias de membros da elite política brasileira - ideias sobre as quais eles atuaram e que configuram a maneira pela qual atuaram -, mas isso não é o mesmo que argumentar que a política brasileira é produto de uma cultura profundamente enraizada na hierarquia, autoritarismo e corpora- 
tivismo, presente no Brasil desde o período colonial até a atualidade. Argumentos sobre uma cultura autoritária são equivocados por duas razões. Em primeiro lugar, essa visão da cultura, na verdade, nega a importância das ideias porque elas perdem seu status de articulações conscientes da percepção de pessoas e tornam-se estruturas cognitivas valores, atitudes e crenças implícitas, que configuram ações sem uma consideração consciente. Segundo, determinantes culturais enraizados são comprovadamente difíceis de testar empiricamente e não resistem bem aos testes que já lhes foram sugeridos. Tanto que, se confiarmos em pesquisas de opinião, valores culturais operacionalizados como atitudes para com certos termos-chave em resposta a perguntas do inquérito variam largamente dentro da América Latina, sendo essa variação indistinguível da propagação de valores ao redor do mundo (Turner, 1995) ${ }^{3}$. Instituições políticas são construções humanas, e ideias políticas são articulações 116 conscientes de desejos, valores, preferências e afins.

Não se nega o papel de condições objetivas, de estruturas ou de atitudes e valores implícitos, simplesmente se argumenta que é necessário considerar ideias como fatores de causa ao longo do desenvolvimento político. A ligação entre a história das ideias e política comparada encontra-se no impacto das ideias durante períodos de reestruturação política e no papel do discurso na legitimação ou subversão da ordem política (Helo, 1996; Cerny, 1990). Sem necessariamente atribuir um poder de causa primordial às ideias, é importante considerar o conteúdo intelectual das lutas políticas. Na situação brasileira, a transplantação de teorias e ideologias políticas europeias para um país dominado por um Estado altamente burocrático de um lado e uma oligarquia poderosa do outro

\footnotetext{
${ }^{3}$ É claro que o valor de pesquisas de opinião pública como fonte de conhecimento está aberto à discussão. Para uma crítica contundente de política comparativa e pesquisas nacionais em geral e o projeto de Cultura Cívica, em específico, ver MacIntyre (1978).
} 
resultou em uma série de mutações, transformações e adaptações das ideologias originais (Schwarz, 1992). Por exemplo, a apropriação do vocabulário liberal e democrático tem sido importante para a articulação de novas relações políticas, demandas por representação, e afirmações de legitimidade dos detentores do poder e seus oponentes. Nesse processo, foram conferidos novos significados a velhos termos; e meios e fins, aparentemente incompatíveis, foram atrelados em estratégias de transformação política. Esse desenvolvimento vai além da simples imitação e envolve a reconceitualização criativa de modelos estabelecidos, como afirmou Fernando Henrique Cardoso a respeito da criatividade de pensadores latino-americanos após a Segunda Guerra Mundial, quando eles reinterpretaram ideias econômicas ortodoxas:

"A reafirmação de ideias em novos contextos, longe de ser um processo meramente repetitivo, implica enriquecimento. [...] A trajetória de uma mesma ideia em outro contexto histórico e cultural a torna uma outra coisa" (Cardoso, 1977, p. 44).

Desta forma, o estudo do pensamento político brasileiro possibilita a exploração do discurso do desenvolvimento político por meio de um caso no qual os limites do Estado e da sociedade sofreram negociações e renegociações. Ao enfocar as maiores tendências do pensamento político, é possível determinar o que estava em risco intelectualmente, ideologicamente e normativamente nos debates sobre a articulação entre Estado e sociedade, um assunto cuja importância cresce na medida em que as dificuldades de estabelecer democracias liberais no modelo do hemisfério norte se evidenciam em diversas partes do mundo.

\section{Inovação, recuperação, imitação e desenvolvimento}

O problema de desenvolver instituições políticas para um novo Estado pode ser encarado de três formas. Primeiro, 
instituições podem ser criadas pela inovação, quebrando com a tradição e formulando instituições inteiramente novas ou partindo de precedentes históricos disponíveis para os criadores, mas bem além de suas próprias experiências ou tradições. Tal foi o caso do uso de ideias do clássico "regime misto" pelos fundadores americanos para as instituições adotadas pela nova república, que foi muito além da experiência colonial ${ }^{4}$. Segundo, instituições podem ser desenvolvidas a partir de tradições e experiências históricas indígenas, como afirmam o autoritarismo "tradicional", o "caminho socialista birmanês", ou tentativas de fundamentar políticas nas práticas africanas de consulta e consenso como forma de evitar competição e conflito entre grupos étnicos. Terceiro, podem existir imitações de exemplos estrangeiros, como o "modelo de Westminster", legado do Império Britânico às suas antigas colônias.

A primeira abordagem é limitada pela questão práti118 ca de se criar algo que seja novo e eficaz no contexto de problemas políticos imediatos. Se a preocupação básica dos que tomam decisões sobre formas políticas é estabelecer uma autoridade eficiente, as ofertas radicalmente novas não provam nem eficiência, nem a legitimidade associada com a familiaridade. Até mesmo a possibilidade de inovação baseada em precedentes históricos é entravada por esses problemas, apesar de que, ao recorrer à história, existe a possibilidade de se fortalecer a legitimidade de instituições que têm um pedigree respeitado. $\mathrm{O}$ sucesso parece necessitar de um grau de encaixe entre o design institucional e as condições reais, o que requer sorte e um bom planejamento. De fato, o experimento anglo-americano de inovação insti-

\footnotetext{
${ }^{4}$ O modelo clássico também teve influência na França revolucionária e na América Latina. Simon Bolívar sustentou os exemplos de Roma, Atenas e Esparta em seu "Discurso de Angostura" em 1819 e modelou explicitamente as instituições da Constituição Boliviana de 1826 nos traços desses regimes. Lecuna e Bierck (1951), pp. 192, 194, 596-606.
} 
tucional demonstra não apenas que as possibilidades estão abertas, mas também a importância do acaso na descoberta de novos caminhos. (Apesar de a República Holandesa e a monarquia polonesa Rzeczpospolita terem sido contemporâneas do novo Estado americano, aparentemente nenhum dos dois teve qualquer influência sobre os fundadores dos Estados Unidos). Parte dessa fortuna, possivelmente, está relacionada com a posição dos Estados Unidos na periferia do mundo do Atlântico norte na época desse experimento. Como um observador notou, inovações institucionais e ideológicas parecem surgir em Estados menos influentes, e não nos mais poderosos. A razão disso pode ser o incentivo para quebrar com o status quo, gerado pela intersecção da pressão para acompanhar os Estados mais poderosos com a falta de oportunidades de avanço para os Estados mais pobres e fracos dentro do sistema internacional (Markoff, 1999). Outros exemplos de tentativas de criação de novas instituições por meio da inovação ou pela influência de precedentes históricos distantes de tradições indígenas incluem os diversos "poderes executivos coletivos" da Revolução Francesa, os sovietes da Revolução Russa, os conselhos de fábrica na Itália em 1920 e as organizações anarquistas das regiões basca e catalã na Espanha durante o período entre guerras e a Guerra Civil. Em contraste com a estabilidade de mais de dois séculos do experimento americano, o sucesso desses outros experimentos pode ser considerado, no mínimo, limitado.

Dentre as limitações da segunda abordagem está a dificuldade em recuperar a experiência indígena. Em primeiro lugar, instituições tradicionais de autoridade política podem depender de condições sociais que mudaram e formas que foram deslocadas nos processos que tornam necessário o estabelecimento de um novo regime político. Outra dificuldade é que a experiência com influências exógenas muda a estrutura de conhecimento na qual as tradições são interpretadas. $\mathrm{O}$ significado e a aceitabilidade das tradições 
podem ser mudados por este fato, o que complica o resgate de formas indígenas. Isso é verdadeiro principalmente porque essa recuperação implica a rejeição de influências exógenas, considerando que o conhecimento e a experiência com influências exteriores só serão desfeitos mediante um alto custo a ser pago. Um exemplo particularmente trágico disso é, obviamente, o caso do Camboja, governado pelos Khmers Rouges, cuja ambição de apagar as influências externas numa tentativa de purificar e reconstruir o país resultou nas mortes de mais de um milhão de cambojanos, fato amplamente documentado (Burgler, 1990; Chandler, 1991; Etcheson, 1984; Kernan, 1985). Outro exemplo pode ser o Sendero Luminoso peruano, que, segundo alguns observadores, vinculou o maoísmo a tradições andinas apocalípticas (Anderson, 1987; Ansion, 1984; Koppel, 1993). Contudo, essa interpretação é contestada vigorosamente por outros observadores que argumentam que o ponto de vista de Sen120 dero era completamente estrangeiro à tradição peruana, sendo uma reação à penetração capitalista na agricultura de terras altas (Poole e Renique, 1991) ou o produto de um racionalismo iluminista hipertrofiado e de um entusiasmo com a Revolução Cultural de Mao (DeGregori, 1997).

É preciso dizer que, em vários casos, as "tradições" que foram resgatas têm servido de fachada para diversas formas de autoritarismo, frequentemente baseadas em tradições menos aceitáveis misturadas a formas bem modernas de controle político. Por exemplo, a alegação do regime birmanês de que estava criando um caminho para o socialismo baseado em valores comunais tradicionais era uma fraude. Sob o falso pretexto da "tradição", uma ditadura militar convencional, baseada no controle das mais modernas instituições políticas, numa burocracia centralizada e nas Forças Armadas, saqueou o país (Silverstein, 1977; Chirot, 1994). A República Islâmica do Irã pode ser outro exemplo: com o pretexto da religião e tradição acoberta-se um autorita- 
rismo carismático baseado na combinação de mobilização das massas, coerção física e ideológica, políticas econômicas populistas, e o comprometimento de diversos elementos dessa sociedade (Dabashi, 2000; Saeidi, 2001).

Finalmente, seguindo a expansão e a hegemonia europeias, a maioria dos novos Estados tem, ao menos inicialmente, adotado modelos de autoridade política tirados da experiência da região do Atlântico norte, historicamente incluindo a variante do Estado socialista que pareceu ser bem-sucedido entre a crise do liberalismo europeu no período entre guerras até o colapso da União Soviética. Tais modelos representam um desenvolvimento político de êxito, assim como os modelos econômicos vindos de países avançados representam o caminho para o desenvolvimento econômico. Contudo, enquanto a imitação de exemplos estrangeiros é uma estratégia poderosa porque envolve os modelos triunfantes facilmente disponíveis, ela não é, como pode parecer inicialmente, uma estratégia simples para a criação de novos regimes.

A imitação pode falhar como estratégia para estabelecer novos regimes, uma vez que a limitada imitação de outros Estados pode ser um substituto, e não uma estratégia para uma reforma sistemática. Por exemplo, parece evidente que, no encontro entre uma Europa expansionista e as sociedades africanas e asiáticas do século XIX que foram colonizadas, a adoção de armas, vestimentas e condutas europeias pelas sociedades não europeias não teve tanto o objetivo de reformar instituições já existentes imitando os Estados europeus, como teve o objetivo de indicar o status do mandante diante de seus súditos e diante de estrangeiros, ao associá-lo aos símbolos europeus de poder. Considere, por exemplo, a adoção de canhões de estilo europeu pelos chineses que agiam sob influência do "Movimento de Autofortalecimento". As reações contra as tentativas de modernização pela imitação dos europeus levaram à descrença e à rejeição dos 
reformadores, e os canhões se transformaram em "totens de modernidade" para comandantes militares em vez de serem usados efetivamente como artilharia de batalha (Porch, 2001, pp. 124-125). Diferentemente do Rei Kamehameha, que adotou armas de pólvora, treinou as tropas nativas como atiradores, adaptou táticas havaianas tradicionais às novas tecnologias e, como resultado, unificou as ilhas (Tregaskis, 1973).

Em determinadas circunstâncias, a imitação da parafernália da civilização europeia pode parecer ter sido mais uma tentativa de atingir o poder europeu por meio de alguma mágica sem a raiz deste poder do que uma tentativa de modernização. Alguns exemplos desse tipo de imitação são os cultos aos carregamentos nas ilhas do Pacífico, que procuravam incentivar o retorno dos europeus com seus "carregamentos", ao imitarem suas vestimentas e conduta, sem um conteúdo substantivo, ou os Herero, da Namíbia, que

122 começaram a usar roupas que tinham como modelo o uniforme do exército colonial da Alemanha Imperial, acreditando que a vestimenta alemã lhes daria o poder de vencer os alemães na rebelião de 1906. Deve ser notado que essa forma de interpretação é contestada em algumas áreas da literatura antropológica atual, que defende a existência de uma maior sofisticação e uma imitação eficiente nas sociedades colonizadas, e não a visão mais antiga e aparentemente fetichista dos cultos de carregamento do sul do Pacífico.

Contudo, apesar desses casos, a imitação como estratégia de criação de um novo regime não irá necessariamente simplificar o trabalho de se criar instituições e de se desenvolver legitimidade. Muito pelo contrário, a disputa de modelos políticos, encontrada entre elites dirigentes e elites oposicionistas dos novos Estados, frequentemente provoca conflito acerca do caminho correto para o desenvolvimento político. Até mesmo quando a imitação é adotada como forma de modernização podem surgir discordâncias quanto ao modelo 
a ser desenvolvido, às mudanças de que a imitação necessita e à reconciliação dos dois lados na criação de um regime.

A imitação, em sua forma mais simples, tem uma natureza "emblemática”. É a adoção de ideias, instituições, formas ou valores estrangeiros como "emblemas" que simbolizam poder, progresso ou civilização. Tal imitação cresce e desvanece com a força aparente do modelo, como indicam os comentários de William Grade sobre o "sistema mimético de governo pautado pelas normas do liberalismo político", que surgiu na América Latina no século XIX, e na breve discussão de Juan Linz sobre o caráter "mimético" de muitos regimes autoritários do período entre guerras (Glade, 1969, pp. 185-186; Linz, 1975, pp. 269, 271, 275-277). Tais emblemas podem ser essencialmente simbólicos ou podem efetivamente assinalar obrigações normativas que servem de medida do grau de sucesso da estratégia de imitação. Apesar de existir uma diferença entre "emblemas" de modernidade, que pretendem servir de fachada ou obter status através da vinculação com o modelo, e a obrigação normativa com os valores dos modelos, o que implica um desejo de cumprir um ideal (Jutkowitz, 1977), em ambos os casos a hipótese subjacente é a de que existe um modelo de desenvolvimento cujos traços indicam a conquista ou, ao menos, um progresso em direção a um determinado status associado com os Estados que são identificados como exemplares. A importância da "democracia" como um símbolo da modernidade no mundo contemporâneo tem sido observada frequentemente. Para se ter uma ideia dessa importância basta consultar um almanaque político da Guerra Fria e ver a quantidade de Estados que insistiram na natureza "democrática" ou "popular" de seus regimes, ou o entusiasmo pelas eleições em diversas ditaduras e Estados unipartidários. Da mesma maneira é possível apontar diversos projetos de desenvolvimento em países do Terceiro Mundo que parecem ter tido nenhum outro objetivo além 
de sugerir modernidade ou de trazer status industrial. Aparentemente todos os países queriam suas próprias companhias de petróleo nacionais e suas próprias fábricas de aço, independentemente da utilidade econômica.

A propagação, por efeito demonstrativo, de constituições e instituições políticas constitucionalistas pela periferia europeia no século XIX foi, de acordo com alguns relatos, imitação emblemática. De acordo com este argumento, diversos Estados da periferia europeia, que eram atrasados social e economicamente, adotaram constituições liberais e instituições políticas como "emblemas de modernidade", indicando sua reivindicação a serem reconhecidos pelos principais Estados europeus. Países como Portugal, Espanha, Sérvia e Romênia tentaram imitar as formas dos Estados avançados da Europa porque algum segmento na elite política nacional acreditava que o progresso precisava de tal imitação, apesar da ausência de condições econômicas que possibilitassem a 124 ascensão das classes ou devido a elas, associadas com as instituições, práticas e valores do liberalismo (Luebbert, 1991, citando Janos, 1984). Argumentos parecidos foram feitos a respeito da proliferação de constituições escritas na América Latina após a independência e a justificativa recorrente de golpes que apelavam para o constitucionalismo; ambos os argumentos estão relacionados com o desejo de assegurar que os Estados latino-americanos entrassem na comunidade das "nações civilizadas" por compartilharem dos mesmos traços políticos (Loveman, 1993; Markoff e Barreta, 1988).

Essa imitação simbólica reiteradamente gerou efeitos reais, talvez perversos, na política e na economia da periferia. Em primeiro lugar, o preço de replicar as formas dos Estados avançados, principalmente suas instituições visíveis, como os exércitos modernos e burocracias, ultrapassava de longe os recursos gerados pelos sistemas econômicos relativamente primitivos desses países, fazendo, portanto, que a imitação da modernidade fosse perniciosa e não benéfica. Janos não usa 
o termo "emblemas de modernidade". mas enfatiza a propagação de padrões de consumo e comportamento, material e intelectual da Europa industrial para a periferia da Europa como "símbolos de uma conduta civilizada" (Janos 1989). Isso também parece ser verdade quando aplicado à América Latina, onde os gastos militares foram bem menores do que na Europa, mas os Estados extraíam bem menos da receita pública de suas populações do que os Estados europeus e dependiam de empréstimos do exterior para pagar guerras internas e externas. O resultado disso foi que a América Latina tinha o

"pior dos dois mundos: exércitos que lutavam sem capacidade para dominar; e coagiam sem argumentos. Enquanto consumia grandes quantidades de dinheiro, o Exército não proporcionava uma forma de custear seus próprios gastos” (Centeno, 1997, pp. 1.583-1.585, 1.604).

Até mesmo o Brasil, que sofreu bem menos com a destruição do começo do século XIX, deparou-se com o problema de não poder pagar por seu verniz europeu apenas com seus recursos internos, o que gerou um endividamento constante em razão de projetos públicos e investimentos.

Em segundo lugar, até mesmo a imitação emblemática mais básica pode ter um significado profundo para a legitimidade de um regime por causa de compromissos normativos implicados pela adoção de "emblemas de modernidade". Em resumo, a adoção de emblemas dos Estados mais avançados pode enfraquecer a posição da elite política existente, ao pressionar a capacidade organizacional e fiscal do Estado e ao mudar as alegações de legitimidade aceitáveis. Mudança esta que ocorre de forma não intencional e até mesmo não desejada pela elite que a adota como base de seu poder.

$\mathrm{Na}$ realidade, modelos de Estados avançados têm sido adotados na expectativa de que suas operações irão induzir as mudanças desejadas na sociedade local. Essa aborda- 
gem é similar à primeira, na medida em que compartilha da crença de que a adoção de certos traços dos Estados avançados irá resultar numa convergência com as condições desses Estados, mas ela é, em maior medida, uma estratégia de desenvolvimento autoconsciente. Se os devidos arranjos constitucionais e institucionais são estabelecidos, então seu funcionamento tranquilo irá resultar na transformação da sociedade como um todo. Pelo menos na visão de alguns teóricos do desenvolvimento, essa estratégia pode ser encontrada nas constituições que foram influenciadas pelos exemplos dos Estados Unidos e da França. Aparentemente, via a Constituição de Cádiz na Espanha, em 1812, líderes políticos latino-americanos, no período da independência, "imaginaram que os lucros econômicos da liberdade derivariam da forma política” (Apter, 1967, pp. 92-93). A confirmação dessa visão pode ser encontrada nos escritos de Frei Caneca, que copiou preceitos da Declaração 126 dos Direitos do Homem e Cidadão francesa diretamente para o seu Bases para a formação do pacto social, e argumentou que a prosperidade brasileira poderia ser assegurada pela definição das instituições de governo corretas (Caneca, [1824]1976). Duas gerações depois, o prodígio liberal Aureliano Tavares Bastos colocaria o mesmo argumento na base de sua relevante crítica do Império (Tavares Bastos, 1870). Essa convicção aparece repetidamente na literatura de ciência política do século XIX e início do século XX, e aparece também, de forma não esperada, na crença de que sociedades tradicionais poderiam ser modernizadas simplesmente se os valores corretos fossem encorajados através da criação de instituições modernas. Essa visão é encontrada nos teóricos de uma modernização supostamente não institucional, da escola desenvolvimentista, e, estranhamente, ecoa no retorno recente do institucionalismo na literatura sobre democratização e transições para a economia de mercado. Das reformas institucionais recomendadas pelo FMI 
e pelo Banco Mundial em seus relatórios sobre economias em transição, aos debates sobre presidencialismo ou parlamentarismo, a ênfase está na organização dos tipos corretos de instituições para incentivar a estabilidade e o crescimento da "sociedade civil" ou "cultura civil", modelada a partir dos Estados industriais avançados. Em resumo, o objetivo da imitação nessa abordagem é incentivar a modernização (novamente, a imitação dos Estados avançados) através da prática (Mitrany, 1975; Lijphart, 1992; Linz e Valenzuela, 1994; Baaklini e Desfosses, 1997; Weimer, 1997).

Finalmente, a imitação frequentemente envolve a adaptação de modelos estrangeiros às circunstâncias específicas do novo local, dado o entendimento de que as diferenças nas condições tornam a simples cópia pouco prática, caso seja esperado que os modelos importados produzam resultados semelhantes. O êxito requer não apenas a adoção de modelos estrangeiros, mas também a sua apropriação e assimilação nas condições locais, processo esse que modifica tanto os modelos quanto as condições nas quais eles são introduzidos. ${ }^{5}$ Nesse ponto, a reflexão política sobre o modelo e a realidade pode se tornar parte do processo e do problema do desenvolvimento, uma vez que intelectuais locais e atores políticos buscam encaixar sua própria visão e seus interesses no modelo, comparando o funcionamento do sistema local com o seu entendimento do modelo.

Obviamente, a adaptação de modelos estrangeiros já era uma realidade prática em muitas partes do mundo "em desenvolvimento" muito antes de ser um tema analisado pelos cientistas sociais do mundo "desenvolvido", como elucida a experiência da América Latina (Gootenberg, 1993). Assim

\footnotetext{
${ }^{5}$ Tal adaptação de modelos às condições locais foi extremamente popular entre defensores do chamado "Modelo Asiático", mas não foi nem limitado nem original a observadores da Ásia, tendo sido comum na literatura sobre a América Latina desde a década de 1950, até mesmo diante da teoria de modernização ingênua (Chee-Meow, 1977; Sinha e Kao, 1988; Garnaut et al., 1995; Veliz, 1965 e 1967).
} 
era no Brasil, no século XIX e início do século XX, onde o modelo liberal (mas não democrático) que foi incorporado pela elite foi adaptado de tal forma às condições brasileiras através de uma série de reformas, conscientes e inconscientes, que funcionava de uma maneira claramente inconsistente com os princípios que o justificavam. O equilíbrio do sistema conseguiu ser mantido até que as mudanças sociais trazidas pelo seu próprio funcionamento geraram tensões que encontraram articulação na contraelite, levada à oposição devido a essa inconsistência. Assim, o regime se tornou alvo de uma intensa crítica política, cuja intenção era deslegitimá-lo, em preparação para a sua substituição por outro grupo de instituições que iriam alcançar o que o liberalismo "disfuncional" tentou conseguir, mas fracassou. A resposta ao fracasso do sistema adaptado variou entre reivindicações de uma imitação mais fiel ao modelo original, quando o modelo liberal havia sido conscientemente adaptado às condições 128 brasileiras de forma a alterar seu funcionamento, e pedidos para adaptação do modelo às especificações brasileiras, mesmo que as tentativas passadas tivessem alcançado resultados perversos. Desta forma, ideias estrangeiras foram adotadas, transformadas para se encaixarem nas circunstâncias locais e se tornaram parte integral da realidade política brasileira, para, em seguida, serem objeto de crítica.

Esse padrão de imitação, adaptação e assimilação, que resultou em tendências opositoras ao próprio modelo, fluiu naturalmente das ambições do modelo liberal. Quando existe um modelo de progresso, existe também seu correspondente, ou seja, uma ideia de atraso a ser superado, o que forma a reação dos progressistas quanto às condições de sua própria sociedade - é a segunda parte dessa dupla tarefa. Para aqueles que veem sua própria sociedade como "atrasada", há uma grande pressão para seguir o modelo avançado, imitando os símbolos e signos da sociedade avançada a qual lhes serve de modelo e, se necessário, impondo as instituições e práticas do 
modelo na sociedade "atrasada" e, em muitos casos, resistente. Isso requer a concentração do poder numa autoridade central capaz de vencer a resistência ao modelo modernizador. Por isso, a ironia das ditaduras modernizadoras que forçam seu povo a ser livre, pelo menos enquanto se libertam das correntes da tradição, como fez Pedro, o Grande, ao forçar que barbas fossem aparadas e ao adotar proscrições legais contra a vestimenta nobre tradicional; e Kemal Ataturk, que proibiu o "fez" e impôs a escrita romana na Turquia. Em ambos os casos, meios autoritários foram empregados com propósitos liberais. Felizmente para aqueles que queriam modernizar o Brasil adotando modelos liberais da Europa, existiam exemplos de liberalismo não democrático que buscavam forçar mudanças em sociedades relutantes. De José Bonifácio de Andrada e Silva adiante, pensadores brasileiros que buscavam a modernização olhariam para os exemplos europeus de Hobbes, Bentham, os Saint-Simonianos no Segundo Império de Napoleão III, e os economistas nacionalistas alemães.

Até mesmo onde um modelo é implementado sem conflitos sérios acerca das alternativas, as condições sociais, que diferem das do terreno original das instituições criadas, irão afetar seu funcionamento nos novos Estados. A interação entre novas instituições liberais e condições não europeias (não liberais) pode ser desanimadora para futuros Estados que atualmente tentam seguir o modelo de desenvolvimento e estabelecer regimes constitucionais e liberais. $\mathrm{O}$ fracasso das instituições adotadas pode minar sua legitimidade e, por fim, a legitimidade de todo o modelo de autoridade política que elas representam. Tal desilusão com os modelos ocidentais no Terceiro Mundo não é, de forma alguma, fato sem precedentes. A história de estudos sobre as áreas africanas está repleta de decepções seguidas e constante desencantamento com os vários modelos europeus de modernidade, levando Basil Davidson a sugerir que, talvez, os "problemas africanos necessitem da aplicação de solu- 
ções africanas, em vez de 'lições de cultura externa'" (1994, p. 13). Ironicamente, esse sentimento é a repetição de outro, encontrado entre os europeus e seus filhos coloniais, incluindo os nacionalistas criollos da América Latina durante o período de independência, os eslavófilos da Rússia, do século XIX, e os movimentos nacionalistas e modernistas do Brasil no início do século XX.

Como resultado do desencantamento com as instituições liberais copiadas do estrangeiro, é possível que exista também um desenvolvimento do modelo dos intelectuais dos Estados "atrasados", em que haja uma pressa em usar as instituições existentes ou de criar instituições que preencham o espaço social político e econômico que foi deixado vazio pelo "atraso" do país. Nesse ponto, o modelo liberal se torna um objetivo a ser atingido, e não um plano ou guia de ação no presente, e a estratégia política pode se transformar em uma autoridade estatal centralizada, diferenciando-se do 130 modelo liberal. Assim, o liberalismo para de guiar a construção de instituições e se torna alvo de críticas por seu fracasso em superar as deficiências da sociedade que deveria ter sido transformada por ele. Esse foi o caso do Brasil no século XIX e início do século XX. Entretanto, a reação contra o liberalismo da República Velha permaneceu extremamente enraizada no liberalismo como um ideal. Apesar de certas tendências, o antiliberalismo no Brasil não virou uma fantasia antiurbana, romântica, agrária, como o nazismo ou o maoísmo, e tampouco se tornou uma luta revolucionária e heróica contra a sociedade burguesa, como o trotskismo ou a nova esquerda. Ao invés disso, o objetivo dos críticos do liberalismo era alcançar fins liberais - desenvolvimento econômico, integração política e econômica, liberdade civil, fim do poder oligárquico rural - através de meios não liberais. $\mathrm{O}$ destino das instituições e ideias liberais no Brasil, as respostas a esse destino, e a crítica ao liberalismo (especialmente à emulação de instituições liberais) que cresceram da expe- 
riência brasileira podem oferecer lições importantes sobre a transferência de instituições políticas liberais para condições que diferem imensamente daquelas nas quais essas instituições foram desenvolvidas inicialmente.

\section{As ironias liberais do autoritarismo}

A adoção e a absorção dos modelos do norte do Atlântico pelo Brasil ocorreram em três etapas de caminhos paralelos. Em primeiro lugar, ideias do norte do Atlântico foram adotadas pelos intelectuais brasileiros; em seguida, essas ideias foram adaptadas segundo as condições particulares do Brasil, frequentemente com resultados extremamente diversos, antes de serem transformadas, enfim, em novas ideias que se diferenciavam das originais em aspectos bastante significativos, o que possibilitava que servissem como instrumentos de crítica aos modelos do norte do Atlântico. Em segundo lugar, no que diz respeito às instituições, houve um processo semelhante no qual instituições foram copiadas e, em seguida, adaptadas às condições locais em um período de experimentação, para finalmente se estabelecerem em um sistema funcional que lembra o original em determinados aspectos, mas tinha sua própria lógica de operação - lógica esta que afetava constantemente as condições de base do sistema, até quando as reproduzia. A interação entre ideias e instituições nesses processos interligados era complexa e nem sempre de amparo mútuo, uma vez que os diferentes ciclos resultavam ou em instituições domésticas sendo alvo de crítica, ou na irrelevância de ideias que não acompanhavam as transformações institucionais e sociais. Mas havia uma sequência clara desses processos paralelos de imitação, adaptação e assimilação.

Apesar da variação nos ciclos de ideias e instituições, é possível definir diversos períodos da história brasileira que foram caracterizados por esses ciclos. O final do período colonial (mais ou menos entre 1780 e 1815) foi caracterizado pela imitação na esfera das ideias, em que as iluministas 
foram adotadas e o liberalismo constitucional se tornou o modelo para a mudança política. O período entre a elevação do Brasil a reino dentro do Império Português, em 1815, e o fim da Revolta Farroupilha, em 1845, foi de adaptação e experimentação, intelectualmente e institucionalmente. O Segundo Reinado (1840-1889) viu a assimilação do liberalismo em uma configuração peculiar brasileira de economia escrava e sociedade hierárquica. A República, que sucedeu o Império, foi estabelecida em imitação aos Estados Unidos, mas as condições locais rapidamente exigiram a adaptação do modelo de um regime constitucional e liberal para uma sociedade ainda hierárquica. Essa adaptação se deu na forma da política dos governadores, na qual instituições liberais eram efetivamente colonizadas pelas oligarquias estatais e chefes políticos, cujo domínio político era baseado em relações sociais clientelistas e poder privados. Os anos do entre guerras presenciaram a apropriação do discurso liberal como um 132 meio de criticar a República Velha, a partir de seus próprios princípios, e culminou na assimilação do modelo estatal de desenvolvimento, dominante na Europa continental desde o fim do século XIX, como forma de alcançar a meta de uma sociedade moderna, industrial e de massa. Esse encaixe não é perfeito, mas o padrão parece claro: a imitação de ideias e modelos estrangeiros é seguida de um período de adaptação e experimentação até que um grau de estabilidade será alcançado através da assimilação do modelo pelas condições sociais brasileiras. A estabilidade desse período é, apesar disso, temporária, pois a assimilação reproduz estruturas sociais que não aparecem no padrão original, e o discurso do arquétipo é apropriado pelos críticos para atacar os fracassos da variante brasileira em seus pontos mais vulneráveis.

A imitação de instituições políticas de Estados avançados deveria ter modernizado o Brasil ao torná-lo liberal no pressuposto de que a existência dessas instituições iria promover o desenvolvimento de outros aspectos, criando assim uma 
sociedade liberal. Curiosamente, essa estratégia de desenvolvimento através da imitação do modelo liberal constitucionalista forneceu grande parte do ímpeto para a tendência estatista do pensamento brasileiro, tanto como resultado de sua lógica interna quanto como uma reação a ela. Essa estratégia envolveu tentativas de adoção de instituições políticas, práticas e ideias da Europa e dos Estados Unidos, apesar das diferenças entre as condições locais e as condições dos modelos. As diferenças não eram vistas como empecilhos à adoção das formas do norte do Atlântico; ao contrário, as diferenças entre o Brasil e os modelos a serem imitados seriam superadas exatamente pela adoção e implementação das ideias estrangeiras. A transformação do Estado iria supostamente preceder e provocar a transformação da sociedade brasileira. Porém, na falta de uma base social para políticas liberais, os modernizadores têm usado repetidamente de meios não liberais de destruição dos traços de "atraso" da sociedade tradicional para a recriação da sociedade em uma nova forma liberal. Apesar de não ser o exemplo mais completo, o Brasil mostrou esse padrão repetidamente na extinção de Canudos, o apoio oferecido ao Estado Novo por liberais tradicionais como Francisco Campos, e os teóricos militares do pós-guerra que justificaram sua conspiração contra o regime civil em nome da liberdade e da defesa da "civilização" contra ameaças da União Soviética e de populistas demagogos (da Cunha, 1902; Campos, 1941; Couto e Silva, 1981) ${ }^{6}$.

\footnotetext{
${ }^{6}$ Nicholas Shumway oferece um retrato parecido desse processo na Argentina, em que os liberais de Buenos Aires se valeram de meios autoritários quase desde a independência, proclamando as virtudes do livre-comércio, liberdade individual e governo representativo, ao mesmo tempo que assassinavam seus oponentes e sujeitavam as províncias a décadas de guerra e embargos comerciais para "civilizá-las". Shumway até nota o agora notório uso do termo "desaparecer" como um eufemismo para o assassinato de oponentes políticos em um ensaio de uma coleção de biografias, Galeria de celebridades argentinas, 1857, editada por dois líderes liberais argentinos do meio do século XIX, Mitre e Sarmiento. Shumway, 1991, pp. 204-205.
} 
A estratégia de imitação também era vulnerável à critica de que criou uma situação de desencontro entre as instituições e pretensões do Estado de um lado e, de outro, as condições materiais e sociais nas quais o Estado existe. Retiradas das condições que lhes deram origem e faltando conexões com as condições a que foram importadas, as instituições e práticas dos modelos dos Estados modernos podem ser descritas como "ideias fora do lugar" (Schwarz, 1992). Nessa perspectiva, o sistema mimético, carecendo de uma base nas condições sociais reais, é incapaz de formular uma resposta programática para a situação na qual foi inserido. Tais desencontros têm sido tema político de preocupação permanente para o pensamento político e social brasileiro; a incumbência de resolvê-los tem normalmente recaído sobre o Estado. A transformação do Brasil em um Estado-nação moderno, apesar da perceptível ausência de condições ou traços sociais encontrados nos modelos de modernidade, deve ocorrer 134 através do desenvolvimento de formas políticas enraizadas na experiência nacional, e não em modelos importados. A ideia de uma busca por soluções nacionais autênticas para o problema da modernização não é, porém, simplesmente uma rejeição de modelos ou experiências estrangeiras. Pelo contrário, existe uma grande ênfase na adaptação da experiência dos outros, principalmente porque o fim almejado é a condição de modernidade alcançada por outros Estados.

Apesar da diferença entre imitação e a solução "nacional", o desejo por desenvolvimento levou ao foco o Estado como agente de modernização, usurpando funções sociais até quando traços e práticas sociais mais antigas permaneceram postos, alterando as novas instituições, importadas ou nacionais, de formas inesperadas, como assinalou Gerschenkron com respeito ao desenvolvimento econômico da Europa oriental (1962, cap. 1). As ambiguidades e contradições do desencontro entre o país legal e o país real, engendradas pela importação de instituições políticas, práticas e ideias liberais, 
forneceram o ímpeto para o desenvolvimento de uma tradição política dominante que associava modernização e desenvolvimento a um Estado forte, até mesmo quando esse desenvolvimento estivesse ligado explicitamente a fins liberais e constitucionalistas. De fato, uma suposição comum do pensamento político brasileiro tem sido o de que o cultivo, a preservação e a garantia da liberdade requerem um Estado forte precisamente porque a ameaça à liberdade é o poder local e privado, não o Estado. O produto dessa tradição é a visão curiosa de liberdade, em que um Estado poderoso e centralizado é posto como um pré-requisito necessário para o desenvolvimento de uma sociedade livre.

O elemento estatista do pensamento político brasileiro, até em suas formas liberais, está enraizado nas tradições de pensamento e nas condições sociais, políticas e econômicas do Brasil. O pensamento político brasileiro foi largamente influenciado pelo Iluminismo e cientificismo do início do século XIX, nos quais a política deveria ser subordinada ao entendimento científico da sociedade. Nessa tradição, exemplificada pela escola positivista, mas enraizada geralmente na crença iluminista no progresso do conhecimento, o entendimento científico da sociedade oferece respostas definitivas a problemas sociais, transformando a política em administração de uma sociedade organizada de acordo com as regras do desenvolvimento social. O produto desse cientificismo iluminista foi a combinação do liberalismo com o antipluralismo e estatismo. O Estado se torna o gerente das políticas recomendadas pela ciência, e a política, quando não é meramente uma distração, é reduzida à representação da sociedade na discussão sobre qual a melhor forma de implementar essas diretrizes, sem aceitar a existência de uma falta de acordo fundamental quanto à natureza da organização social. Essa tendência, chamada de "objetivismo" por Bolivar Lamounier em seu estudo da ideologia autoritária no Brasil, é notável por sua prevalência tanto na 
esquerda como na direita, no Brasil no século XX (1974, pp. 309-10, 315-16, 322-23). A versão mais extrema dessa visão pode ser a "ditadura republicana", vislumbrada pelos positivistas ortodoxos do Apostolado, e pelos chamados "jacobinos", que trabalhavam para derrubar o Império na escola politécnica militar, mas elementos dela podem ser encontrados em pensadores como José Bonifácio Andrada e Silva, o conhecido patriarca da independência brasileira, passando pelos corporativistas do início do Estado Novo, até os intelectuais militares do "Grupo Sorbonne" do pós-guerra, que buscavam sistematizar a organização de objetivos políticos nacionais através de treinamento da administração moderna (Reis de Queiroz, 1986; Viotti da Costa, 1985; Love, 1996; Bacchus, 1990).

A consolidação da ênfase estatista no pensamento político brasileiro avançou mais ainda com os repetidos fracassos de instituições liberais importadas de Estados mais avan136 çados para promover uma modernização adequada ou para assegurar uma estabilidade. Somando a isso, o fato de que os ganhos mais óbvios do Brasil no desenvolvimento econômico vieram sob o Estado Novo de Vargas, talvez não seja surpreendente que o Estado forte e intervencionista tenha se tornado o modelo de desenvolvimento nacional tanto para a esquerda quanto para a direita, dos críticos da República Velha ao auge do governo militar. Contudo, no auge da dominação da sociedade pelo Estado, o governo militar linha-dura de 1967-1974, houve um recuo do estatismo tanto da esquerda quanto da direita. Durante a abertura, quando a sociedade se tornou arena da oposição ao Estado, as possibilidades liberais e antiestatistas do Atlântico norte se tornaram modelos atraentes de desenvolvimento político.

Em uma das maiores ironias da história brasileira, a possibilidade de uma política genuinamente liberal apareceu como resultado de um dos regimes mais centralizados e autoritários que o país já conheceu. Em 1973, no auge do 
governo militar linha-dura do general Garrastazu Médici, Fernando Henrique Cardoso publicou um artigo em que articulava a estratégia política de resistência ao governo militar enfatizando não a luta armada ou a mobilização política das massas, mas o desenvolvimento de organizações sociais não políticas. O artigo foi um chamado para a criação de laços de solidariedade horizontal entre cidadãos que compartilhavam interesses de forma não ameaçadora para o monopólio do governo militar. Cardoso enfatizou que essa estratégia não visava a desafiar o regime politicamente, mas sim assegurar o espaço social para a proteção de direitos e interesses. Em resumo, Cardoso apelou pela "reativação da sociedade civil", entendendo-a como o espaço público habitado por cidadãos qua cidadãos. O desenvolvimento subsequente de organizações sindicais, comunidades eclesiais de base patrocinadas pela Igreja, associações de bairro e grupos de direitos humanos, isso sem mencionar o revigoramento e a cooperação entre associações profissionais e grupos de interesses da elite, foi acompanhado pela criação de vínculos entre esses grupos e a oposição política com a aprovação e incentivo do novo presidente militar. Esse processo foi notável não apenas pelo papel do governo militar em incentivar o desenvolvimento de pressões sociais compensatórias, mas também pelo recuo do estatismo da esquerda brasileira.

Foi um efeito irônico do regime burocrático-autoritário dos anos 1960 aos 1980 que substituiu, até certo ponto, o velho acesso clientelista aos legisladores que alguns setoreschave da sociedade possuíam no período anterior pela tomada de decisão tecnocrata de dentro do Estado. De maneira curiosa, os esforços dos regimes militares em isolar as tomadas de decisão das pressões "políticas" de grupos sociais ajudaram a criar circunstâncias dentro das quais a organização civil da sociedade se tornou possível e desejável. A limitação do clientelismo e o acesso pessoal ao Estado, consequentemente, criaram uma situação em que uma ética de cidadania mais 
universalista e autônoma é possível. Além disso, os governos militares impeliram (e, por vezes, até incentivaram) o desenvolvimento de uma sociedade civil ativa na forma de oposição política e de movimentos sociais que desenvolveram os laços de solidariedade horizontal que Oliveira Vianna, por exemplo, esperava que o Estado corporativista desenvolvesse.

Desde o fim do governo militar, com o recuo da centralização e do Estado intervencionista, o liberalismo político e econômico (em seu sentido europeu, não norte-americano) tem sido novamente importado na esperança de propiciar transformações sociais. Neste contexto, a crítica "autoritária instrumental" da República Velha, com sua análise da interação das instituições liberais e condições sociais não liberais, pode servir como um aviso para não permitir que preocupações liberais ou modelos neoliberais do Estado mínimo causem a degeneração da política em formalismo. Vale a pena lembrar que o Estado não precisa ser visto como 138 inimigo da sociedade civil. De fato, essa visão é demasiado pura e apolítica e pode transformar o Estado em inimigo dos aspectos universais e igualitários da cidadania e possibilitar o retorno à política clientelista acobertada pelo argumento de democracia liberal.

O sonho de uma significativa parcela das elites imperiais e republicanas era transformar o Brasil por meio da introdução no país de instituições europeias ou norte-americanas. Contudo, o processo de mudança foi complexo e não apenas uma questão de adaptação dos brasileiros a ideias e modelos aprendidos com a Europa. Enquanto ideias e instituições adotadas como imitação do mundo externo mudaram a sociedade na qual foram introduzidas, os modelos finalmente foram assimilados às estruturas políticas, sociais e econômicas existentes no Brasil e mudaram no processo. Essa assimilação não foi simplesmente cópia ou uma seleção de elementos de modelos, mas foi a interação entre modelos e condições. Como resultado, mesmo que retoricamente, ideias e princípios políticos defendidos 
pelos brasileiros no século XIX foram retirados do liberalismo e do republicanismo inglês, norte-americano e francês; o liberalismo e republicanismo no Brasil foram adaptados à cultura de uma sociedade e economia baseadas na escravidão, da mesma maneira que o republicanismo no sul dos Estados Unidos adotou traços peculiares (Genovese, 1994).

Essa adaptação de ideias e modelos estrangeiros foi tanto uma escolha consciente de pensadores e atores políticos que buscaram implementá-los quanto uma consequência inadvertida das interações desses modelos e ideias com as condições locais. Através de sua assimilação, os modelos e ideias importadas tiveram efeitos nas condições locais, conceitualmente, em termos de como essas condições eram entendidas, e, praticamente, em termos das próprias práticas locais se adaptando ao funcionamento das novas instituições. Até mesmo quando os brasileiros reagiram contra as ideias do Atlântico norte que permeavam sua sociedade pós-colonial, como fizeram contra as instituições liberais da República Velha, insistindo em soluções brasileiras para problemas brasileiros, muitas das alternativas propostas também eram baseadas em ideias e modelos estrangeiros. Essas ideias também adquiriram características locais que as mudaram substantivamente em diversos sentidos, o que viabilizava as afirmações de que seu caráter era nacional mesmo quando a imitação avançava rapidamente. Assim, todo o processo de imitação, adaptação e assimilação era, em parte, um exercício intelectual com efeitos concretos, mas servia também como matéria-prima para outra reflexão, feita por pensadores brasileiros sobre os problemas do desenvolvimento que, por si só, podem iluminar a articulação de ideias políticas e seu papel no desenvolvimento político. A transformação criativa de ideias estrangeiras tem certa relevância para o estudo de mudanças políticas, e a experiência brasileira pode muito bem oferecer algo a ser aprendido pelos estudiosos da metrópole. 


\section{Referências bibliográficas}

ADDIS, C. 1997. "A clash of paradigms". Latin American Research Review, vol. $32, \mathrm{n}^{\circ} 3$.

ALMOND, G. A.; VERBA, S. (eds.). 1963. The civic culture: political attitudes and democracy in five nations. Princeton, NJ: Princeton University Press.

ALVAREZ, S. 1990. Engendering democracy in Brazil: women's movements in transition politics. Princeton: Princeton University Press.

AMES, B. 1987. Political survival: politicians and public policy in Latin America. Berkeley: University of California Press.

ANDERSON, J. 1987. Sendero Luminoso: a new revolutionary model? London: Institute for the Study of Terrorism.

ANSION, J. 1984. "Es luminoso el camino de Sendero?”. In: El cristianismo ante el Perú en el 1985: crisis económica, violencia. Lima: Centro de Proyección Cristiano.

APTER, D. E. 1967. The politics of modernization. Chicago: University of Chicago Press.

BAAKLINI, A. I.; DESFOSSES, H. (eds.). 1997. Designs for democratic stability: studies in viable constitutionalism. Armonk, NY: M. E. Sharpe.

; NOEUX, G. de; SPRINGBORG, R. 1999. Legislative politics

in the Arab world: the resurgence of democratic institutions. Boulder, CO: Lynne Rienner.

BACCHUS, W. A. 1990. Mission in mufti: Brazil's military regimes, 1964-1985. Wesport, CT: Greenwood Press.

BURGLER, R. A. 1990. The eyes of the pineapple: revolutionary intellectuals and terror in Democratic Kampuchea. Saarbrücken: Verlag Breitenbach.

BURKE, P. 1996. "History". In: KUPER, A.; KUPER, J. (eds.). The Social Science Encyclopedia. $2^{\text {nd }}$ ed. London/New York: Routledge.

CAMPOS, F. 1940. O Estado nacional. Rio de Janeiro: José Olympio.

CANECA, F. 1976. Ensaios políticos. Rio de Janeiro: Documentário/ PUC-RJ.

CARDOSO, F. H. 1977. "The originality of the copy: ECLA and the idea of development”. Centre of Latin American Studies Working Papers, no 28. Cambridge University.

; FALETTO, E. 1979. Dependency and development in Latin America. Berkeley: University of California Press.

CENTENO, M. A. 1997. "Blood and debt: war and taxation in nineteenth century Latin America”. American Journal of Sociology, vol. 102, n 6 , May, pp. 1.565-1.605.

CERNY, P. G. 1990. The changing architecture of politics: structure, agency, and the future of the State. London: Sage Publications. 
CHANDLER, D. 1999. Brother number one: a political biography of Pol Pot. Boulder: Westview Press.

CHEE-MEOW, S. (ed.). 1977. Asian values and modernization. Singapore: Singapore University Press.

CHIROT, D. 1994. Modern tyrants. Princeton, NJ: Princeton University Press.

COHEN, J. L.; ARATO, A. 1992. Civil society and political theory. Cambridge, MA: MIT Press.

COMAROFF, J.; COMAROFF, J. (eds.). 1993. Modernity and its malcontents: ritual and power in postcolonial Africa. Chicago: University of Chicago Press.

COSTA, E. V. da. 1985. The Brazilian empire: myths and histories. Chicago: University of Chicago Press.

COUTO E SILVA, G. do. 1982. Geopolítica do Brasil e a conjuntura nacional. Rio de Janeiro: José Olympio.

CUNHA, E. da. [1901]1944. Rebellion in the Backlands. Trans. Samuel Putnam. Chicago: University of Chicago Press.

DABASHI, H. 2000. "The end of Islamic ideology". Social Research, vol. 67, issue 2, Summer, pp. 475-528.

DAVIDSON, B. 1992. The black man's burden: Africa and the curse of the Nation-State. New York/London: Times Books.

Random House.

DEGREGORI, C. I. 1997. "The limits of Sendero Luminoso". In: CAMERON, M.; MAUCERI, P. (eds.). The Peruvian labyrinth. University Park, PA: Pennsylvania State University Press.

DENNETT, D. C. 1995. Darwins dangerous idea: evolution and the meanings of life. New York: Simon \& Schuster.

ETCHESON, C. 1984. The rise and demise of Democratic Kampuchea. Boulder: Westview.

FRANK, A. G. 1967. Capitalism and underdevelopment in Latin America. New York: Monthly Review Press.

1969. Latin America: underdevelopment or revolution? New York:

Monthly Review Press.

GARNAUT, R.; GRILLI, E.; RIEDEL, J. (eds.). 1995. Sustaining export-oriented development: ideas from East Asia. New York: Cambridge University Press.

GEDDES, B. 1994. Politicians dilemma: building State capacity in Latin America. Berkeley: University of California Press.

GENOVESE, E. D. 1994. The Southern tradition: the achievement and limitations of an American conservatism. Cambridge, MA: Harvard University Press. 
GERSCHENKRON, A. 1966. Economic backwardness in historical perspective. Cambridge, MA: Belknap Press.

GLADE JR., W. P. 1969. The Latin American economies. New York: American Books.

GOOTENBERG, P. 1993. Imagining development: economic ideas in Peru's fictitious prosperity of Guano, 1840-1880. Berkeley: University of California Press.

HARRISON, L. E. 1985. Underdevelopment is a state of mind: the Latin American case. Lanham, MD: University Press of America. ; HUNTINGTON, S. (eds.). 2001. Culture matters. New York: Basic Books.

HELD, D. 1996. Models of democracy. Stanford: Stanford University Press.

JANOS, A. C. 1982. The politics of backwardness in Hungary, 1825-1945. Princeton, NJ: Princeton University Press. . 1989. "The politics of backwardness in continental Europe, 1780-1945”. World Politics, vol. 41, n 3, April.

JEDLICKI, J. 1999. A suburb of Europe: nineteenth-century Polish approaches to Western civilization. Budapest: Central European University Press.

JUTKOWITZ, J. M. 1977. "Ideology, values, and public freedom: an essay assaying the historical context”. In: BLACHMAN, M. J.; HELLMAN, 142 R. G. (eds.). Terms of conflict: ideology in Latin American politics. Philadelphia: Institute for the Study of Human Issues.

KAPLAN, M. 1987. Democracy and civil society. London: Verso. . 1995. Neither cargo nor cult: ritual politics and the colonial imagination in Fiji. Durham, NC: Duke University Press.

KEANE, J. (ed.). 1988. Civil society and the State. London: Verso.

KECK, M. 1992. The workers party and democratization in Brazil. New Haven, CT: Yale University Press.

KIERNAN, B. 1985. How Pol Pot came to power: a history of communism in Kampuchea, 1930-1975. London: Verso.

KOPPEL, M. 1993. Peru's shining path: anatomy of a reactionary sect. New York: Pathfinder Press.

KUMAR, K. 1993. "Civil society: an inquiry into the usefulness of an historical term”. British Journal of Sociology, vol. 44, n 3, September.

LAMOUNIER, B. 1974. "Ideology and authoritarian regimes: theoretical perspectives and a study of the Brazilian case”. Los Angeles: Ucla. Dissertation.

LANDES, D. 1999. The wealth and poverty of nations. New York: W. W. Norton. LECUNA, V.; BIERCKE, H. A. (eds.). 1951. Selected writings of Bolívar. New York: Colonial Press. 
LIJPHART, A. 1992. Parliamentary versus presidential government. New York: Oxford University Press.

LINZ, J. J. 1975. "Authoritarian and totalitarian regimes”. In: GREENSTEIN, F. I.; POLSBY, N. W. (eds.). Handbook of political science: macropolitical theory. Reading PA: Addison-Wesley. Vol. 3.

; VALENZUELA, A. (eds.). 1995. The failure of presidential democracy. Baltimore, MD: The Johns Hopkins University Press.

LOVE, J. L. 1996a. Crafting the Third World: theorizing underdevelopment in Romania and Brazil. Stanford: Stanford University Press.

1996b. "Economic ideas and ideologies in Latin America since 1930". In: BETHELL, L. (ed.). Ideas and ideologies in twentieth century Latin America. Cambridge: Cambridge University Press.

LOVEMAN, B. 1993. The constitution of tyranny. Pittsburgh: University of Pittsburgh Press.

LUEBBERT, G. M. 1991. Liberalism, fascism, or social democracy: social classes and the political origins of regimes in interwar Europe. New York: Oxford University Press.

MACINTYRE, A. 1978. "Is a science of comparative politics possible?". In: MACINTYRE, A. Against the self-images of the age. Notre Dame, IN: University of Notre Dame Press.

MARKOFF, J. 1999. "From center to periphery and back again: reflections on the geography of democratic innovation”. In: HANAGAN, M.; TILLY, C. (eds.). Extending citizenship, reconfiguring States. Lanham, MD: Rowman and Littlefield.

; BARRETTA; S. R. D. 1988. "Brazil's abertura: a transition from what to what?”. In: MALLOY, J. M.; SELIGSON M. A. (eds.). Authoritarians and democrats: regime transitions in Latin America. Pittsburgh: University of Pittsburgh Press.

MORSE, R. M. 1964. "The heritage of Latin America”. In: HARTZ, L. (ed.). The founding of new societies. New York: Harcourt, Brace, Jovanovich. 1989. New world soundings: culture and ideology in the Americas. Baltimore, MD: The Johns Hopkins University Press. 1992. "Toward a theory of Spanish American government". In: WIARDA, H. J. Politics and social change in Latin America: still a distinct tradition? Boulder, CO: Westview Press. . 1996. "The multiverse of Latin American identity, 1920-1970". In: BETHELL, L. (ed.). Ideas and ideologies in twentieth century Latin America. Cambridge: Cambridge University Press.

O'DONNELL, G. 1973. Modernization and bureaucratic authoritarianism. Berkeley: Institute of International Studies, University of California Press. 
POCOCK, J. G. A. 1973. The Machiavellian moment: Florentine political thought and the Atlantic Republican tradition. Princeton: Princeton University Press.

POOLE, D.; RENIQUE, G.1991. "The new chroniclers of Peru: U.S. scholars and their shining path of peasant rebellion”. Bulletin of Latin American Research, vol. 10, $\mathrm{n}^{\circ} 1$.

PORCH, D. 2001. Wars of empire. London: Cassell Publishers.

QUEIROZ, S. R. R. de. 1986. Os radicais da República \& Jacobinismo: ideologia e ação 1893-1897. São Paulo: Brasiliense.

RAHE, P. A. 1992. Republics ancient and modern: classical republicanism and the American Revolution. Chapel Hill, NC: University of North Carolina Press.

SAEIDI, A. A. 2001. "Charismatic political authority and populist economics in post-revolutionary Iran”. Third World Quarterly, vol. 22, issue 2, April.

SCHNEIDER, B. R. 1991. Politics within the State: elite bureaucrats and industrial policy in authoritarian Brazil. Pittsburgh, PA: Pittsburgh University Press.

SCHWARZ, R. 1992. Misplaced ideas: essays on Brazilian culture. Trans. and ed. John Gledson. London: Verso.

144 SEIDMAN, G. 1994. Manufacturing militance: workers movements in Brazil and South Africa, 1970-85. Berkeley: University of California Press.

SELIGMAN, A. 1992. The idea of civil society. New York: Free Press.

SHUMWAY, N. 1991. The invention of Argentina. Berkeley: University of California Press.

SILVERSTEIN, J. 1977. Burma: military rule and the politics of stagnation. Ithaca, NY: Cornell University Press.

SINHA, D.; KAO, H. S. R. (eds.). 1988. Social values and development: Asian perspectives. Newbury Park CA: Sage Publications.

TAVARES BASTOS, A. C. [1861]1976. Os males do presente e as esperanças para o futuro. São Paulo: Nacional.

. [1870]1937. A província: Estudo sobre a descentralização no Brazil. São Paulo: Companhia Editora Nacional.

TAYLOR, C. 1979. "Interpretation and the sciences of man". In: RABINOW, P.; SULLIVAN, W. M. (eds.). Interpretive social science: a reader. Berkeley and Los Angeles: University of California Press.

THOLFSEN, T. R. 1984. Ideology and revolution in modern Europe: an essay on the role of ideas in history. New York: Columbia University Press.

TREGASKIS, R. 1973. The warrior king. New York: Macmillan.

TURNER, F. C. 1995. "Reassessing political culture”. In: SMITH, P. (ed.). Latin America in comparative perspective. Boulder, CO: Westview Press. 
VELIZ, C. (ed.). 1965. Obstacles to changes in Latin America. Oxford: Oxford University Press. . (ed.). 1967. The politics of conformity in Latin America. Oxford: Oxford University Press. 1980. The centralist tradition of Latin America. Princeton, NJ: Princeton University Press.

WEIMER, D. L. 1997. The political economy of property rights: institutional change and credibility in the reform of centrally planned economies. New York: Cambridge University Press.

WIARDA, H. J. 1973. "Toward a framework for political change in IbericLatin tradition: the corporative model”. World Politics, January. 1979. Corporatism and national development in Latin America. Boulder: Westview Press. 1992. "Introduction: social change, political development, and the Latin American tradition". In: WIARDA, H. J. (ed.). Politics and change in Latin America: still a distinct tradition? Boulder, CO: Westview Press, $3^{\text {rd }}$ ed. 2002. The soul of Latin America: The cultural and political tradition. New Haven: Yale University Press.

WOLFE, J. 1993. Working women, working men: São Paulo and the rise of Brazil's industrial working class. Durham, NC: Duke University Press.

WOLIN, S. 1973. "The politics of the study of revolution”. Comparative Politics, April. 


\section{PROGRESSO E MIMESIS: IDEIAS POLÍTICAS, IMITAÇÃO E DESENVOLVIMENTO}

ROBERT CHISHOLM

A ciência política comparativa vinha ignorando o papel central que ideias e modelos políticos têm na criação e no desenvolvimento das instituições. Com o colapso do bloco soviético e o fervor intelectual que acompanhou esse evento, criou-se uma abertura pela qual os efeitos do pensamento político passaram a ser vistos como importantes. Articuladas por pensadores políticos, as ideias dirigem ações, refletem entendimentos dominantes entre as elites sobre a realidade ou fornecem uma base para a crítica desses entendimentos. Nesse sentido, seu estudo pode revelar alguns aspectos do esforço de constituição de um regime. Este artigo sugere uma forma de abordar o problema: examinar como as ideias são adotadas, adaptadas e assimiladas pelos atores políticos.

Palavras-chave: Ciência política; Progresso; Mimesis; Ideias políticas; Imitação; Desenvolvimento.

\section{PROGRESS AND MIMESIS: POLITICAL IDEAS, IMITATION, AND DEVELOPMENT}

Comparative political science has ignored the central role that political ideas and models have on the creation and development of institutions. With the collapse of the Soviet bloc and the intellectual 
fervor that accompanied this event, possibilities of paying attention to the effects of political thought grew. Articulated by political thinkers, ideas direct actions, reflect dominant understandings among elites on the truth or provide a basis for criticism of these understandings. In this sense, their study may reveal some aspects of the effort to set up a regime. This article suggests an approach to the problem: focusing on how ideas are adopted, adapted and supported by the political actors.

Keywords: Political science; Progress; Mimesis; Political ideas; Imitation; Development. 